(C) Copyright 2020: Editum. Servicio de Publicaciones de la Universidad de Murcia. Murcia (Spain) ISSN print edition: 0212-9728. ISSN online edition (http://revistas.um.es/analesps): 1695-2294 Online edition License Creative Commons 4.0: BY-SA

\title{
Difficult temperament and social maladjustment in childhood: The mediating role of family environment
}

\author{
Ester Ato*, Ma . Dolores Galián, and Mª . Ángeles Fernández-Vilar
}

Universidad de Murcia

\begin{abstract}
Título: Temperamento difícil y desajuste social en la niñez: El papel mediador del ambiente familiar.

Resumen: El objetivo de este estudio fue analizar el papel mediador del ambiente familiar en la relación entre temperamento difícil y problemas externalizantes/internalizantes en una muestra de 474 niños españoles de entre 6 y 8 años. Un segundo objetivo fue analizar el efecto del género en el patrón de mediación encontrado. Para la medida de los problemas externalizantes/internalizantes, el ajuste marital, las prácticas parentales y el temperamento del niño los padres cumplimentaron la Batería de Socialización (BAS-1), el Test de Ajuste Marital (MAT) y la versión española del Cuestionario de Temperamento en la niñez intermedia (TMCQ). El análisis de mediación probado confirmó el efecto de mediación del ajuste marital y las prácticas parentales de implicación y disciplina en la relación entre temperamento difícil y problemas externalizantes, y el efecto de mediación del ajuste marital y la implicación parental en la relación entre temperamento y difícil y problemas internalizantes. Por otro lado, los resultados apuntaron un patrón de mediación diferente cuando comparamos a niños y niñas. En concreto, encontramos que el efecto de mediación del ajuste marital y la implicación parental fue más fuerte en niños que en niñas.

Palabras clave: Temperamento difícil; Ajuste marital; Prácticas parentales; Desajuste social; Mediación.
\end{abstract}

\begin{abstract}
The aim of this work was to analyze the mediating role of family environment in the relationship between difficult temperament and externalizing/internalizing problems in a sample of 474 Spanish children aged between 6 and 8 years. A secondary objective of this work was to analyze the effect of gender in the mediation pattern found. To measure externalizing/internalizing problems, marital adjustment, parenting practices and children's temperament, the parents were given a Socialization Battery (BAS-1), the Marital Adjustment Test (MAT), the Spanish version of the PCRI (Parent-Child Relationship Inventory), and the Temperament in Middle Childhood Questionnaire (TMCQ). We tested a statistical mediation model that revealed the mediating role of marital adjustment, and the parenting practices of involvement and limit setting, in the relationship between difficult temperament and externalizing problems. We found that marital adjustment and parental involvement mediated the relationship between internalizing problems and difficult temperament. On the other hand, the results pointed to a different mediation pattern when we compared boys and girls. Specifically, we found that the mediating role of marital adjustment and parental involvement in the relationship between difficult temperament and externalizing problems was stronger in boys than in girls.

Keywords: Difficult temperament; Marital adjustment; Parenting; Social maladjustment; Mediation.
\end{abstract}

Temperament has been defined as constitutionally individual differences in reactivity and self-regulation, influenced by maturation and experience (Rothbart, 1981). Due its biological nature, temperament becomes evident in the early stages of development, and it is measurable by children's emotional arousal and self-regulation (Rothbart, 1981). According to Rothbart, child temperament can be described by three broad-factors: surgency/extraversion (e.g. approaching responses, smile and laugh, sensation seeking), negative emotionality (e.g. anger, frustration, fear, sadness) and effortful control, defined as the ability to suppress a dominant response to perform a subdominant response (Rothbart \& Bates, 1998), with the last two factors being those most related to socioemotional outcomes (Eisenberg, Spinrad, \& Eggum, 2010). As for negative emotionality and its relation to behavior problems, previous research has sought to establish different pathways between temperamental characteristics and externalizing/internalizing problems, with anger being more related to externalizing problems (Muris, Meesters, \& Blijlevens, 2007; Rydell, Berlin, \& Bohlin, 2003), and fear more related to internalizing ones (Muris et al., 2007). However, the findings are contradictory (Nozadi, Spinrad, Eisenberg, \& Eggum-Wilkens, 2015; Lemery, Essex, \& Smider, 2002), which has led to negative emotionality frequently being used to predicts both externalizing and internalizing problems (Delgado, Carrasco, González-Peña \& HolgadoTello, 2018; Edwards \& Hans, 2015; Kochanska \& Kim, 2013; Walters, 2014; Wittig \& Rodriguez, 2019a; 2019b).

Along with negative emotionality, effortful control is the
Ester Ato Lozano. Departamento de Psicología Evolutiva y de la Educación. Campus de Espinardo-30100 Murcia (Spain). E-mail: esterato@um.es (Article received: 11-02-2020; revised: 29-03-2020; accepted: 14-04-2020) 
temperamental factor that has received most support in the prediction of social outcomes, having shown a positive relation with externalizing (Jonas \& Kochanska, 2018; Olson, Choe \& Sameroff, 2017; Díaz et al., 2017) and internalizing problems (Brajsa-Zganec \& Zanjec, 2014). Studied together, negative emotionality and effortful control has led to the "difficult temperament" concept, first introduced by Thomas and Chess (1977), which describes, from the Rothbart perspective, high negative emotionality and poor effortful control children (Putnam, Sanson \& Rothbart, 2002). Hence, difficult temperament is seen as a biologically based risk factor that increases the probability of poor social outcomes (Kim \& Deater-Deckard, 2011; Kochanska \& Kim, 2013; Lengua \& Wachs, 2012). Indeed, difficult temperament has been associated with higher levels of externalizing (Delgado et al., 2018; Wang, Eisenberg, Valiente, \& Spinrad, 2015), and internalizing problems (Muthadie, Zhou, Eisenberg, \& Wang, 2013; Patel, 2019). One possible explanation to this relation is proposed by the vulnerability model (Nigg, 2006), which assume that certain types of temperament predispose children to problematic behavior, particularly in certain contexts. According to this model, more negative and less regulated children are more likely to be ineffective in their social interactions, which consequently would increase the probability of their showing aggressiveness, disruptive behavior, depression or anxiety, among other disorders. Although a possible overlap between temperament and behavior problem measures has been suggested, from the vulnerability model it is assumed that temperamental characteristics and problematic behavior do not reflect the same underlying structure (Karreman, de Haas, van Tuijl, van Aken, \& Dekovic, 2010), and this assumption has been corroborated elsewhere (Egger \& Angold, 2006; Lemery et al., 2002).

Another factor that has proved to have strong relations with children's social development is family environment. According to the family systems theory, "family is a whole formed by interrelated subsystems, each affecting and being affected by the others" (Pedro, Ribeiro \& Shelton, 2012, p.509). One of the most relevant family subsystems is that of the parenting practices chosen in the socialization process. In the literature on the relation between parenting and social outcomes, parenting warmth, involvement and control have proven to be crucial in children's social adjustment, predicting both internalizing and externalizing problems (Serbin, Kingdon, Ruttle, \& Stack, 2015). In this regard, parental warmth and involvement is considered to act as social resource and emotional guidance in children's social interactions, facilitating their adaptation to the environment (Rubin et al., 2004; Zhao, Cheng \& Wang, 2015). In contrast, lower levels of parental warmth and involvement may affect negatively to children's security and self-esteem, resulting in a higher probability of their showing social maladjustment (Ato, Galián \& Fernández-Vilar, 2014). With respect to behavioral control, identified with parental monitoring and supervision, is found to be associated to fewer externalizing problems (Galambos, Barker \& Almedia, 2003; van Prooijen,
Hutteman, Mulder, van Aken, \& Laceulle 2018). This association is particularly relevant in higher-risk environments, where children need limits from their parents to be protected from problematic situations and their peers. In contrast, some research reports that the associations between parental control and internalizing problems show the inverse pattern, especially when it comes to psychological control (Galambos, et al., 2003; Gilliom \& Shaw, 2004). Another relevant family subsystem that could affect children's social outcomes is parents' marital adjustment. From this perspective, aspects of marital adjustment, such as conflict levels or satisfaction with the relationship, could affect the parents' relationship with their child positively or negatively. Just as negative parenting behaviors, marital conflict may lead to a more aggressive and hostile environment, vulnerating children's selfconfidence and predisposing them to social adjustment problems (Hosokawa \& Katsura, 2017). Indeed, lower levels of marital adjustment have been related to higher levels of child behavior problems (Coln, Jordan \& Mercer, 2013; Gamliel, Dollberg \& Levy, 2018; Shigeto, Mangelsdorf \& Brown, 2014). Nevertheless, and in spite of its relevance in children's socioemotional development, the possible mediating effect of marital adjustment has been ignored in the literature on externalizing/internalizing problems, so its implications are not yet well understood.

Although many studies have examined its effects on social maladjustment separately, models taking into account temperament and family environment interactions offer a wider vision of this issue. One of these models raises the mediation effect of parenting in the relation between temperament and social development. Considering the biological nature of temperament and thus its precursor role in a mediational model, difficult temperament is viewed as a risk factor of parenting quality, suggesting that children's temperament influence parent's behavior. An extensive body of research confirms this pattern (Laukkanen, Ojansuu, Tolvanen, Alatupa \& Aunola, 2014; Zadeh, Jenkins \& Pepler, 2010). Therefore, it is assumed that children with different temperaments elicit different reactions in their parents, which can lead to different adjustment outcomes. Particularly, difficult children are found to elicit more negative control and less warmth behavior in their parents, which in turns predicts a worst social adjustment (Lerner, Castellino, Terry, Villarruel, \& McKinney, 1995; Olson, Sameroff, Kerr, López \& Wellman, 2005). However, more research is needed at this point.

Nevertheless, considering the contribution of children's temperament and family environment to social maladjustment is still an insufficient approach to this issue.

Specifically, in order to plan appropriate prevention and intervention programs, it is not only necessary to understand the variables involved in social maladjustment, but also the way that gender affects these relationships. In this line, it is likely that the mediating role of parenting in the relationships between difficult temperament and internalizing/ externalizing problems could be significantly different when 
boys and girls are compared. Although gender differences in temperament (Else-Quest, Hyde, Goldsmith \& Van Hulle, 2006), parenting practices (Keenan \& Shaw, 1997) and externalizing/internalizing problems (Leve, Kim \& Pears, 2005) are well documented separately, there much fewer studies that analyze the potential effect on gender in the interaction of these variables (Karreman, van Tuijl, van Aken, Dekovy, 2009). Moreover, many of these studies offer non-significant or contradictory results. So, although many studies haven't found gender differences in the prediction of children's externalizing problems from temperamental characteristics (Else-Quest et al., 2006; Leve et al., 2005; Rubin, Burgess, Kennedy, \& Stewart, 2003; Olson et al., 2005), Karreman et al. (2009) found that effortful control was more strongly related to concurrent externalizing problems in boys. With regard to internalizing problems, Karevold, Coplan, Stoolmiller \& Mathiesen, (2011) found that activity level acted as a protective factor in the development of internalizing problems for shy boys, but not for shy girls. Regarding connections between gender, family environment and behavior problems, some studies have found that girls are more affected by negative parenting in the explanation of externalizing behavior (Leve et al., 2005; Walters, 2014), compared with boys, while other studies have reported the opposite pattern (McFayden-Ketchum, Bates, Dodge \& Pettit, 1996; Miner \& Clarke-Stewart, 2008). Taking into account the interactions between temperament, family environment and behavioral problems, Karreman et al. (2009) found that boys with low levels of effortful control were at higher risk of showing externalizing problems, but more parental positive control seemed to buffer this risk. Anyway, the moderating effect of gender may be affected by the culture in which children develop. For example, it is expectable that in cultures that are less permissive with boys in relation to negative temperamental signals, the mediational effect of family may be stronger in boys. More research is needed therefore in this area.

To sum up, the first objective of our work was to study the mediating role of family environment (including parenting practices and marital adjustment) in the relationship between difficult temperament and social relationship problems (externalizing/internalizing problems), in a sample of Spanish children in early childhood. This developmental stage is particularly relevant for our objective, given that, on the one hand, it is a period in which family environment exerts a huge influence on children's development, and on the other, it seems to be critical in the beginning of the appearance of externalizing/internalizing problems. Furthermore, a secondary objective of our work was to analyze if the moderating effect of gender plays a role in these mediation patterns. We hypothesized that difficult temperament will be related to social outcomes by impacting on their family environment (parenting and marital adjustment). We also hypothesized that gender could moderate the mediational process between implied variables.

\section{Method}

\section{Participants}

The original sample comprised 474 Spanish children (50.2\% boys and $49.8 \%$ girls) of six $(33.8 \%)$, seven $(37.7 \%)$ and eight $(28.5 \%)$ years old, corresponding to the First Cycle of Primary School (FCPS). The reason to include children of different ages had no longitudinal goal, but was because we wanted to achieve a wider and more representative sample of our population. In this respect, we verified the absence of age differences in all the variables object of this work (see Table 2). The participating families were recruited from several schools in Murcia (Spain). Of all the respondents, $82.7 \%$ were mothers and $75 \%$ had worked during the previous six months. In this sample, $9 \%$ had Primary School studies, 22.1\% had completed Secondary School, 30.4\% held a professional qualification, $26.6 \%$ were university graduates, and $1.1 \%$ held a PhD.

Of all participants, 474 parents completed the temperament questionnaire, 380 parents completed the marital adjustment measure, 428 parents completed the parenting practices measure and 433 completed the social adjustment measure. To discard the fact that parents who did not respond to questionnaires about marital adjustment, parenting and social adjustment might represent a different sample (due to the presence of sensible questions), we conducted a survey with $75 \%$ of participants who did not respond to all the questionnaires.

Analyzing all their responses; forgetting (40\%), lack of time $(38 \%)$, absence from home $(9 \%)$ and others $(14 \%)$, we finally concluded that the final sample used in all the analyses could be representative of the original sample of 474 families.

\section{Procedure}

Schools were visited and a meeting was held with the head teachers to explain the purpose of the project. After consent was given by the school, the questionnaires on temperament (in a first stage), and marital adjustment, upbringing and social adjustment (in a second stage, two months later) were given to the school along with a letter addressed to the volunteer parents with instructions for filling in both questionnaires. A telephone number was also provided for queries.

\section{Measures}

Temperament. The Temperament in Middle Childhood Questionnaire (TMCQ; Simmonds \& Rothbart, 2004) was used to measure temperament. This questionnaire obtains information provided by parents regarding a number of daily situations. The TMCQ includes 160 items on a 5-point Likert scale, grouped into 17 scales to evaluate temperament: (1) Activation Control: The capacity to perform an action 
when there is a strong tendency to avoid it; (2) Activity level: The level of gross motor activity including the rate and extent of locomotion; (3) Affiliation: The desire for warmth and closeness with others, regardless of shyness or extraversion; (4) Anger/frustration: The amount of negative effect related to the interruption of ongoing tasks or goal blocking; (5) Assertiveness/dominance: The tendency to speak without hesitation and to gain and maintain control of social situations; (6) Attentional Focusing: The tendency to maintain attentional focus upon task-related channels; (7) Discomfort: The amount of negative effect related to sensory qualities of stimulation, including the intensity, rate or complexity of light, movement, sound and texture; (8) Fantasy/Openness: Active imagination, aesthetic sensitivity and intellectual curiosity; (9) Fear: The amount of negative affect including unease, worry or nervousness related to anticipated pain or distress and/or potentially threatening situations; (10) High Intensity Pleasure: The amount of pleasure or enjoyment related to situations involving high stimulus intensity, rate, complexity, novelty and incongruity; (11) Impulsivity: The speed of response initiation; (12) Inhibitory Control: The capacity to plan and to suppress inappropriate approach responses under instructions or in novel or uncertain situations; (13) Low Intensity Pleasure: The amount of pleasure or enjoyment related to situations involving low stimulus intensity, rate, complexity, novelty and incongruity; (14) Perceptual Sensitivity: The amount of detection of slight, low intensity stimuli from the external environment; (15) Sadness: The amount of negative affect and lowered mood and energy related to exposure to suffering, disappointment and object loss; (16) Shyness: The rate of inhibited approach in situations involving novelty or uncertainty; and (17) Soothability/Falling Reactivity: The rate of recovery from peak distress, excitement or general arousal. The alpha coefficient for the subscales ranged from .621 to .887 .

Although we have come from a theoretical concept of difficult temperament based on Rothbart's work, which would include dimensions of negative emotionality and effortful control, we wanted to explore if factorial analysis spontaneously revealed this factor in our data. For this purpose, scores on the scales were submitted to Principal Components Analysis (PCA). Indeed, the first factor (Eigenvalue $4.19,24.67 \%$ of variance) reflected the construct of difficult temperament, with Anger, Discomfort, Fear, Sadness and Shyness loading positively, and Activation control and Soothability loading negatively. Scores in this factor $(\mathrm{M}=.00$; $\mathrm{SD}=1.00)$ were used as the measure of the Difficult temperament construct. Its internal reliability was 0.80 (Guttman G6=0.82).

Marital adjustment. In the evaluation of marital satisfaction, we used the Marital Adjustment Test (MAT; Locke \& Wallace, 1959). This test includes 15 items, which evaluate the degree of agreement on relevant topics, and various questions about disagreement, communication, or confidence in the relationship. The scores vary for the different items, and the maximum possible sum of all of them would be 158. The highest scores imply a higher marital satisfaction. We chose this test because it is one of the most used in measuring marital quality (Stanley, Ragan, Rhoades \& Markman, 2012), and its psychometric properties are very good, with an internal reliability of .90 , which enables us to discriminate between distressed and non-distressed couples.

Parenting. To evaluate the parents' educational patterns, the Parent-Child Relationship Inventory was used (PCRI; Gerard, 1994) in its Spanish adaptation (Roa \& Del Barrio, 2001). This questionnaire has seven scales for collecting information: (1) Parental support, which measures the amount of social, emotional and economic support parents feel they are receiving; (2) Satisfaction with parenting, which measures the amount of satisfaction parents feel in their role as parents; (3) Involvement, which measures the degree of interaction, knowledge and acceptance parents believe they have with respect to their children; (4) Communication, which evaluates the parents' perception regarding the effectiveness of their communication with their children; (5) Limit setting, which measures the importance parents give to setting limits, their management, and the perception of children as being problematic; (6) Autonomy, which evaluates parents' attitudes in fostering or facilitating independence in their children; and (7) Role Orientation, which measures parents' beliefs regarding the role of gender in their children's upbringing. One last scale, Social desirability, was used to check the validity of the parents' responses. The alpha coefficients for these subscales were between .566 and .764. In accordance with our objectives, the scales of Involvement (Cronbach $\alpha$ $=.764$ ), and Limit setting (Cronbach $\alpha=$.764) were selected to measure parenting practices.

Social adjustment. The BAS (Batería de socialización; Silva \& Martorell, 1989) in its version for parents (BAS-1) was used to measure the children's socialization profiles. This battery includes 53 items on a 4-point Likert scale grouped into seven scales in order to measure social adjustment in children between 6 and 15 years old. The inhibiting and disruptive aspects include: Aggressiveness/stubbornness, which measures rule resistance, indiscipline, verbal and physical aggression and disruptive behavior; Apathy/social withdrawal, referring to social withdrawal, introversion, isolation, apathy and depressive symptoms; Anxiety/shyness, which measures aspects related to anxiety (fear, nervousness) and to shyness (lowliness, embarrassment). The direct scores of these scales were calculated with a correction sheet. The psychometric properties of this battery are quite adequate, having an internal reliability with a range of .87 to .99 , depending on the subscales. In accordance with our objectives, the Aggressiveness/stubbornness scale was selected as an indicator of externalizing problems, whereas a composite score of the Apathy/social withdrawal and the Anxiety/shyness scales was selected as an indicator of internalizing problems. 


\section{Data analysis}

Data collection was performed using a cross-sectional design with all variables measured. The analyses used in this work would require a longitudinal design, but the nature of our research objectives is worth exploring first with a more simple cross- sectional design.

There were also a considerable number of missing data, particularly $11 \%$ in parental scales and $21 \%$ in marital adjustment. The small number of cases, and ignorance about the missingness pattern, advised us to discard the use of multiple imputation methods (Carpenter \& Kenward, 2013; Hughes, Heron, Sterne \& Tilling, 2019). Then, we used pairwise deletion to rescue the maximum number of cases in each of our analyses.

In order to find answers to our planned research objectives, we conducted several statistical analyses. First, we ran a descriptive analysis with all the variables, by gender and age, and we checked for differences in gender, with the Welch ttest, and in age, with F one- factor ANOVA. We also examined the zero-order Pearson's and first-order partial correlations between predictor and outcomes controlling parenting variables in order to determine if mediators could behave as confounding variables in the relation between difficult temperament and externalizing/internalizing problems. To this end we used version 1.8.12 of $\mathrm{R}$ package psych (Revelle, 2018).

Second, we ran separated analysis of moderated mediation (Muller, Judd \& Yzerbyt, 2005), using Model 59 of conditional mediation as mentioned in Hayes (2013, p.455), with the $\mathrm{R}$ mediation package, version 4.4.7 (Imai, Keele \& Tingley, 2010; Tingley, Yamamoto, Hirose, Keele \& Imai, 2014). All moderated mediation analyses were run using quasi- Bayesian confidence intervals and 5000 bootstrap samples. A set of six different models was fitted using as predictor the indicator of difficult temperament, as separate mediators marital adjustment and parenting scales (involvement and limit setting), as separated outcomes the indicators of externalizing and internalizing problems and gender as moderator. Age was used as a covariate in all analyses. The difference between mediational effects between boys and girls was tested with the program test.modmed included in the $\mathrm{R}$ mediation package.

With pairwise deletion for missing data the number of cases used in each analysis depended on the variables included in the model. Following White and Carlin (2010) and Barlett, Carpenter, Tilling and Vanteelandt (2014), all assumptions required to use pairwise deletion were fullfilled with our data. Multivariate normality was tested with mardia program included in the $\mathrm{R}$ psych package (Revelle, 2018), with $p<.075$ for all variables. The hypothesis of MCAR was tested with LittleMCAR program (Little, 1988) included in the R package BaylorEdPsych (Beaujean, 2015), showing insufficient evidence to reject the MCAR assumption with our data: $\chi^{2}(42)=44.36 ; p=.372$.

\section{Results}

Descriptive analyses of all of the variables included in our sample, separated by gender and age, are shown in Tables 1 and 2. ANOVAs were applied to check for statistically significant differences in the measures used for groups of gender and age. Significant differences were found between boys and girls only for externalizing problems $(F(1,430)=10.287$; $p<.001)$. No significant differences were found with respect to age.

Table 1. Descriptive analysis of main variables subsetting by gender and Welch t-test.

\begin{tabular}{|c|c|c|c|c|c|c|c|c|c|c|}
\hline & \multicolumn{4}{|c|}{ Boys } & \multicolumn{3}{|c|}{ Girls } & \multicolumn{3}{|c|}{ Welch } \\
\hline & $N$ & mean & $S D$ & median & $N$ & mean & $S D$ & median & t-test & $(\mathrm{df})$ \\
\hline (1) & 213 & 3.43 & 0.33 & 3.43 & 214 & 3.43 & 0.32 & 3.43 & -0.01 & $(426)$ \\
\hline (2) & 213 & 2.77 & 0.39 & 2.75 & 214 & 2.83 & 0.40 & 2.83 & 1.58 & (426) \\
\hline (3) & 195 & 4.53 & 0.23 & 4.58 & 185 & 4.50 & 0.43 & 4.61 & 0.15 & (379) \\
\hline (4) & 237 & -0.07 & 1.01 & -0.18 & 233 & 0.07 & 0.99 & 0.03 & 1.57 & (469) \\
\hline (5) & 215 & 9.04 & 5.52 & 8.00 & 217 & 7.73 & 4.79 & 7.00 & $2.68^{* *}$ & (431) \\
\hline (6) & 215 & 6.12 & 4.55 & 5.00 & 217 & 5.88 & 3.85 & 5.00 & 0.64 & (431) \\
\hline
\end{tabular}

(1) Involvement. (2) Limit setting. (3) Marital adjustment. (4) Difficult temperament. (5) Externalizing problems. (6) Internalizing problems.

** $p<.01$ (two-tailed)

Table 2. Descriptive analysis of main variables subsetting by age and $\mathrm{F}$ test.

\begin{tabular}{lrrrrrrrrrrr}
\hline & \multicolumn{3}{c}{ 6-years old } & \multicolumn{3}{c}{ 7-years old } & \multicolumn{2}{c}{ 8-years old } \\
\cline { 2 - 9 } & $N$ & mean & $S D$ & $N$ & mean & $S D$ & mean & $S D$ & & F test \\
\hline$(1)$ & 132 & 3.46 & 0.31 & 170 & 3.44 & 0.32 & 125 & 3.39 & 0.31 & 2.81 & $(2,424)$ \\
$(2)$ & 132 & 2.82 & 0.39 & 170 & 2.79 & 0.40 & 125 & 2.78 & 0.39 & 0.25 & $(2,424)$ \\
$(3)$ & 125 & 4.54 & 0.22 & 143 & 4.49 & 0.43 & 112 & 4.53 & 0.33 & 0.57 & $(2,377)$ \\
$(4)$ & 159 & 0.07 & 1.01 & 177 & 0.07 & 0.99 & 135 & 0.05 & 1.03 & 0.81 & $(2,468)$ \\
$(5)$ & 134 & 8.46 & 4.88 & 171 & 8.80 & 4.79 & 127 & 7.72 & 4.64 & 1.75 & $(2,429)$ \\
$(6)$ & 135 & 5.96 & 4.47 & 172 & 6.17 & 3.85 & 125 & 5.82 & 3.79 & 0.32 & $(2,429)$ \\
\hline
\end{tabular}

(1) Involvement. (2) Limit setting. (3) Marital adjustment. (4) Difficult temperament. (5) Externalizing problems. (6) Internalizing problems. 
Correlation analysis was also used to know the relation between all the implied variables. Table 3 shows that difficult temperament was negatively related to involvement, limit setting and marital adjustment, and positively related to externalizing and internalizing problems. Involvement and limit setting were positively related to marital adjustment and negatively related to difficult temperament, externalizing and internalizing problems.

In order to exclude that parenting styles (involvement and limit setting) and marital adjustment were confounding variables in the relation between difficult temperament and externalizing and internalizing problems, we ran partial correlation analyses controlling parenting styles and marital ad- justment variables. Table 3 shows the zero-order Pearson correlation matrix for main variables with pairwise sample sizes (in brackets) and probabilities adjusted by the Bonferroni-Holm's correction method (Holm, 1979) to control the family-wise error rate. Table 3 also shows the partial correlations obtained when controlling each one of the variables used as mediators in the relation between temperament and deviant behavior. As expected, control variables reduced the weight of zero-order Pearson correlations, but did not change the statistical significance of Pearson correlations between temperament and deviant behavior, so we excluded parenting styles and marital adjustment as confounding variables.

Table 3. Pearson and first-order partial correlations between (4) and (5-6) controlling parenting variables (1-3). Values in brackets are pairwise sample sizes.

\begin{tabular}{|c|c|c|c|c|c|c|c|c|c|}
\hline & \multicolumn{6}{|c|}{ Zero-order Pearson correlations } & \multicolumn{3}{|c|}{ Partial correlations controlling } \\
\hline & $(1)$ & (2) & (3) & (4) & (5) & (6) & (1) & (2) & (3) \\
\hline (1) & 1.00 & & & & & & & & \\
\hline (2) & $0.39^{* *}$ & 1.00 & & & & & & & \\
\hline (3) & $(427)$ & $(427)$ & 1.00 & & & & & & \\
\hline & $0.21^{* *}$ & $0.26^{* *}$ & & & & & & & \\
\hline (4) & $(346)$ & $(346)$ & $-0.22^{* *}$ & 1.00 & & & & & \\
\hline & $\begin{array}{c}-0.15^{*} \\
(424)\end{array}$ & $\begin{array}{c}-0.33^{* *} \\
(424)\end{array}$ & (379) & & & & & & \\
\hline (5) & $-0.30^{* *}$ & $-0.51^{* *}$ & $-0.19^{* *}$ & 0.29 & 1.00 & & 0.25 & 0.15 & 0.24 \\
\hline (6) & $\begin{array}{l}(427) \\
* *\end{array}$ & $\begin{array}{l}(427) \\
*\end{array}$ & $\begin{array}{c}(350) \\
* *\end{array}$ & $\begin{array}{c}(430) \\
* *\end{array}$ & $0.26^{* *}$ & 1.00 & $0.41^{* *}$ & $0.42^{* *}$ & $0.40^{* *}$ \\
\hline (427) & $\begin{array}{c}-0.22 \\
(427)\end{array}$ & $\begin{array}{c}-0.12 \\
(350)\end{array}$ & $\begin{array}{c}-0.20 \\
(430)\end{array}$ & $\begin{array}{c}0.43 \\
(433)\end{array}$ & & & & & \\
\hline
\end{tabular}

Finally, we analyzed the moderator effect of gender with the mediational hypothesis of family environment in the relationship between difficult temperament and social maladjustment. Six different models were run using the indicator of difficult temperament as predictor, indicators of family environment as mediators, indicators of social maladjustment as outcomes, gender as moderator and age as covariate. We also tested the differential effect of gender in all the mediational analyses. Tables 4 and 5 show the main direct, indirect and total effects of the moderated-mediational hypotheses with $95 \%$ confidence intervals for indirect effects and the proportion of mediation for each of the family environment indicators for externalizing and internalizing behavior, respectively. With externalizing behavior as outcome, we found a significant indirect mediation effect with involvement $(0.212, p<.01)$, limit setting $(0.782, p<.001)$ and marital adjustment $(0.189, p<.01)$. The differential gender indirect effect for externalizing behavior was significant for involvement $(0.169, p<.05)$ and marital adjustment $(0.247, p<$ $.01)$, but not for limit setting. With internalizing behavior as outcome, we found a significant indirect mediation effect with involvement $(0.101 ; p<.05)$ and marital adjustment (0.101, $p<.05)$, but not with limit setting. The differential indirect effect of gender with internalizing behavior was not significant in any case.

We also ran a mediational analysis of family environment on the relation between difficult temperament and social maladjustment separately for boys and girls, using twelve different basic models of mediation. We observed that indirect mediation effect for Externalizing behavior as outcome was different with involvement (boys: $0.280, p<$ .01; girls: $0.141, p>.05$ ) and marital adjustment as mediator (boys: $0.299 ; p<.01$, girls: $0.066, p>.05$ ) and it appears to be similar in boys and girls with limit setting as mediator (boys: $0.805, p<.01$; girls: $0.749, p<.01$ ). For Internalizing behaviors, in contrast, the indirect mediation effect was very similar for marital adjustment (boys: 0.098, $p<.05$; girls: $0.099, p<.05$ ), and for involvement (boys: 0.099, $p<.01$, girls: $0.098, p<.01)$ but for limit setting the indirect effect was null. 
Table 4. Mediational hypothesis temperament-family environment-externalizing problems moderated by gender $95 \%$ Confidence Intervals for indirect effects in parentheses.

\begin{tabular}{|c|c|c|c|c|c|}
\hline \multirow[b]{2}{*}{ Mediators } & \multicolumn{4}{|c|}{ Effect } & \multirow[b]{2}{*}{$\%$ Mediated } \\
\hline & $\mathrm{N}$ & Direct & Indirect $(95 \% \mathrm{CI})$ & Total & \\
\hline Involvement & 422 & $1.356^{* * *}$ & $0.212^{* *}(.103 / .314)$ & $1.568^{* * *}$ & $13.2^{* *}$ \\
\hline Boys & 212 & $1.343^{* * *}$ & $0.280^{* *}(.162 / .419)$ & $1.623^{* *}$ & $16.7^{* *}$ \\
\hline Girls & 210 & $1.421^{* *}$ & 0.141 & $1.562^{* *}$ & 8.3 \\
\hline Gender difference & & & $0.169^{*}$ & & \\
\hline Limit setting & 422 & $0.797^{* * *}$ & $0.782^{* * *}(.307 / 1.283)$ & $1.579^{* * *}$ & $49.5^{* * *}$ \\
\hline Boys & 212 & $0.803^{* * *}$ & $0.805^{* * *}(.292 / 1.376)$ & $1.608^{* * *}$ & $50.4^{* * *}$ \\
\hline Girls & 210 & $0.805^{* * *}$ & $0.749^{* * *}(.211 / 1.300)$ & $1.554^{* * *}$ & $48.5^{* * *}$ \\
\hline Gender difference & & & 0.018 & & \\
\hline Marital adjustment & 349 & $1.476^{* * *}$ & $0.189^{* *}(.084 / .305)$ & $1.657^{* * *}$ & $10.5^{* *}$ \\
\hline Boys & 178 & $1.630^{* * *}$ & $0.299^{* *}(.147 / .462)$ & $1.929^{* * *}$ & $14.8^{* *}$ \\
\hline Girls & 171 & $1.269^{* * *}$ & 0.066 & $1.335^{* * *}$ & 4.2 \\
\hline Gender difference & & & $0.247^{* *}$ & & \\
\hline
\end{tabular}
${ }^{*} p<.05 ; \stackrel{* *}{p}<.01 ;{ }^{* * *} p<.001$

Table 5. Mediational hypothesis temperament-family environment-internalizing problems moderated by gender $95 \%$ Confidence Intervals for indirect effects in parentheses.

\begin{tabular}{|c|c|c|c|c|c|}
\hline \multirow[b]{2}{*}{ Mediators } & \multirow[b]{2}{*}{$\mathrm{N}$} & \multicolumn{4}{|c|}{ Effect } \\
\hline & & Direct & Indirect $(95 \% \mathrm{CI})$ & Total & $\%$ Mediated \\
\hline Involvement & 423 & $1.755^{* * *}$ & $0.102^{*}(.016 / .201)$ & $1.793^{* *}$ & $5.2^{*}$ \\
\hline Boys & 213 & $1.745^{* * *}$ & $0.099^{*}(.021 / .172)$ & $1.844^{* *}$ & $5.1^{*}$ \\
\hline Girls & 210 & $1.746^{* * *}$ & $0.098^{*}(.018 / .181)$ & $1.844^{* *}$ & $5.1^{*}$ \\
\hline Gender difference & & & 0.001 & & \\
\hline Limit setting & 423 & $1.889^{* * *}$ & -0.038 & $1.851^{* * *}$ & 0 \\
\hline Boys & 213 & $1.940^{* * *}$ & -0.014 & $1.926^{* *}$ & 0 \\
\hline Girls & 210 & $1.853^{* *}$ & -0.056 & $1.797^{* *}$ & 0 \\
\hline Gender difference & & & -0.033 & & \\
\hline Marital adjustment & 349 & $1.693^{* * *}$ & $0.101^{*}(.035 / .178)$ & $1.794^{* * *}$ & $5.4^{*}$ \\
\hline Boys & 178 & $1.697^{* * *}$ & $0.098^{*}(.032 / .164)$ & $1.795^{* * *}$ & $5.3^{*}$ \\
\hline Girls & 171 & $1.687^{* * *}$ & $0.099^{*}(.037 / .159)$ & $1.786^{* * *}$ & $5.2^{*}$ \\
\hline Gender difference & & & 0.002 & & \\
\hline
\end{tabular}
${ }^{*}<.05 ; \quad{ }^{* *} p<.01 ; \quad{ }^{* * *} p<.001$

\section{Discussion and conclusions}

The proposal of our research was, first, to examine the mediating role of family environment, including parenting and marital adjustment, in the relationship between difficult temperament and internalizing/externalizing problems, and, second, to explore the moderating effect of gender on this mediation. For data collection we used parent reports for all measures, based on the premise that parents are the best source of information about children's behavior at this stage of development.

With respect to our first objective, we found a significant relationship between difficult temperament and externalizing/internalizing problems. Specifically, higher levels of difficult temperament were related to higher levels of externalizing and internalizing problems. This result has been systematically replicated in previous research (Muthadie, et al.,
2013; Wang, et al., 2015). More negatively reactive and less regulated children seem to be less skilled in emotional and social competence and consequently more prone to exhibit psychological disorders, such as disruptive conduct, anxiety or depression, compared with those that are less reactive and better regulated.

Regarding parenting practices, we found a mediating role of involvement and limit setting in the relationship between difficult temperament and externalizing problems.

Although our study is cross-sectional, which obliges us to be very cautious with the interpretation of the results, we assumed that the biological nature of temperament gives it a precursor role in the mediation model. Other cross-sectional studies have posed biological variables as precursor variables (Karreman, et al., 2010). From this approach, our result implies that children perceived by their parents as temperamentally difficult seemed to increase the exhibition of externaliz- 
ing problems by reducing the parents' levels of involvement and discipline. In the same vein, it is to be expected that chidren described by their parents as more negative, highly reactive and less regulated children contributed to a decrease in the parents' involvement and discipline levels, and this pattern ultimately increased the probability of the children displaying disruptive and defiant behavior. This pattern may be particularly relevant at this developmental stage, when the parent-child relationship is still one of dependency, and children benefit as much from their parents' warmth as from adequate limit setting. Consequently, when parents reduce their affect and control signals, children may feel ignored/rejected by their parents, and express their stress and frustration through antisocial and aggressive behaviors. Thus, this result emphasized the negative effect that particular temperamental characteristics had on parenting effectiveness, and the connections of this effect with child psychopathology. This is in line with the "continuum of caretaking casualty" (Sameroff \& Chandler, 1975), where children at biological risk present disruptive behavior only when the parenting is ineffective. Few studies have analyzed this casuistry (Karreman et al., 2010; Putnam et al., 2002).

When the analyses were replicated with internalizing problems, parental involvement showed a mediating effect in the relationship between temperament and behavioral problems, but this effect was not found for limit setting. Thus, children perceived by their parents as more difficult were less supported by them and, as a consequence, exhibited a higher probability of anxiety or depressive behaviors. An explanation for this data may be that, due to their internal nature, anxiety and depression disorders are likely to be less dependent on the limits that parents put on behavior, and their expression does not involve rule defiance, where discipline is highly implicated. In other words, parents' discipline levels are not relevant in the relationship between difficult temperament and internalizing problems due to the very idiosyncrasy of this kind of problem. In contrast, parents' warmth and involvement may affect internalizing psychopathology greatly, particularly in early childhood, where children need their parents' approval to develop adequate selfesteem, and an absence of parental approval could cause anxiety or depression symptomatology. Though scarce, there have been a few studies that have explored similar relationship patterns, but the results have been contradictory (Crawford, Schrock \& Woodruff-Borden, 2011; Van der Bruggen, Stams, Bögels \& Paulussen-Hoogeboom, 2010).

In relation to marital adjustment, we found that this family subsystem significantly mediates the relationship between difficult temperament and both externalizing and internalizing problems. Many studies have reported the effect that difficult temperament exerts on marital adjustment (Ato, Galián \& Fernández-Vilar, 2015; Shigeto et al., 2014; Zimet \& Jacob, 2001), or the combined effect of marital adjustment and difficult temperament on children's behavioral problems (Shigeto et al., 2014), but none that we know of have explored the mediating effect of marital adjustment in the relationship between children's temperament and psychopathology. Therefore, our data suggest that difficult children showed a higher probability of behavioral problems by affecting their parents' marital relationship quality. Marital maladjustment implied higher parental stress levels, which could decrease their parenting effectiveness. Indeed, as we have said previously, in this developmental stage the parent-child relationship is characterized by dependence, and children are likely to be more vulnerable to their parents' responses of stress and rejection, on the one hand, and to their parents' conflict levels, on the other, which often co-exist with a child's fear of family breakup.

With respect to our secondary objective, we explored the moderating effect of gender on the mediation relationships previously reported. In relation to externalizing problems, we found that the degree of mediation is markedly different when we compared boys and girls with regards to marital adjustment and parental involvement but is almost the same with regards to limit setting. Specifically, the mediation effect of marital adjustment and involvement in the relationship between difficult temperament and externalizing problems is stronger in boys. Therefore, it seems that difficult boys are more affected by the rejection signals of parents than difficult girls are. Few studies have shown a higher vulnerability in difficult boys predicting behavior problems, compared with girls (Karreman et al., 2009).

This effect could be due to the parents' gender stereotypes, which lead them to express differently the effect that the child's difficult temperament has on parenting and marital adjustment, resulting in less involvement and more marital conflict in the case of boys. An alternative explanation could be that boys are more sensitive to their parents' conflict and the expression of rejection, which consequently increases their disruptive or aggressive behavior, whereas girls are less vulnerable to these negative signals. This moderating effect of gender was replicated in the mediation of internalizing problems, but only in parental involvement, and less significantly. Moreover, this preliminary analysis suggests that a more detailed analysis is necessary on this point.

In conclusion, we believe that important issues arise from the findings of our study. First, family environment emerges as a key factor in the approach to social maladjustment in children with difficult temperament, and as a result intervention of behavioral problems must keep its relevance in mind. In this sense, our data suggest that not only are parenting practices influential in the explanation of the relationship between temperament and externalizing/internalizing problems, but that marital adjustment is critical too. Furthermore, parenting practices of affect and control mediate the relationship of difficult temperament and social maladjustment in different ways, with involvement being significant for both externalizing and internalizing problems, but discipline only for externalizing ones. 
So, an adequate intervention program of behavioral problems in early childhood must work with children and their parents, taking the aforementioned premises into account. First, interventions with children must be aimed at detecting their problematic temperamental characteristics and giving them strategies oriented at decreasing their level of negative emotionality and improving their level of effortful control. On the other hand, interventions with parents should be aimed at training them in conflict resolution and at giving them information about the most suitable parenting practices, bearing in mind their children's temperament and the kind of behavioral problems they show. There are a large number of early-interventions programs that take into account children's temperament and parents training in other countries (INSIGHTS; McCormick, O'Connor, Cappella, \& McClowry, 2015), but temperamental applications in educational settings in Spain remain unexplored.

The elaboration of intervention programs or adaptations of previews programs would be needed for the Spanish population, in the light of our results. In the same vein, our results suggest that parents must also consider children's gender in interventions on social maladjustment, especially in the case of externalizing behaviors. Specifically, parents must be particularly alert to marital conflict and rejection responses in their interaction with difficult and disruptive boys. Though much more remains to be explored in the moderating effect of gender in maladjustment mediation patterns, these preliminary results suggest the need to

\section{References}

Arango, C., Diaz-Caneja, C. M., McGorry, P. D., Rapoport, J., Sommer I.E., Vortsman, J. A., McDaid, D., Marín, O., Serrano-Drozdowsky, E., Freedman, R. \& Carpenter, W. (2018). Preventive strategies for mental health. Lancet Psychiatry, 5(7), 591-604. DOI: 10.1016/S22150366(18)30057-9

Ato, E., Galián, M.D., \& Fernández-Vilar, M.A. (2014). Gender as predictor of social rejection: the mediating/moderating role of effortful control and parenting. Anales de Psicologia, 30(3), 1069-1078. DOI: https://doi.org/10.6018/analesps.30.3.193171

Ato, E., Galián, M.D., \& Fernández-Vilar, M.A. (2015). The Moderating Role of Children's Effortful Control in the Relation Between Marital Adjustment and Parenting. Journal of Child and Family Studies, 24(11), 3341-49. DOI: 10.1007/s10826-015-0136-4

Barlett, J. W.; Carpenter, J. R.; Tilling, K. \& Vanteelandt, S. (2014). Improving upon the efficiency of complete case analysis when covariates are MNAR. Biostatistics, 15, 719-730.

Beaujean, A. A. (2015). R Package for Baylor University Educational Psychology Quantitative Courses. Available at https://CRAN.Rproject.org $/$ package $=$ BaylorEdPsych.

Bornstein, M. H., Hahn, C., \& Suwalsky, J. D. (2013). Physically developed and exploratory young infants contribute to their own long-term academic achievement. Psychological Science OnlineFirst. DOI:10.1177/0956797613479974

Brajša-Žganec, A., \& Hanzec, I. (2014). Social development of preschool children in Croatia: Contributions of child temperament, maternal life satisfaction and rearing practices. Journal of Child and Family Studies, 23 (1), 105-117. http://dx.di.org/10.10077S10826-012-9696-8.

Carpenter J. R. \& Kenward M. G. (2013). Multiple Imputation and Its Application. Chichester: Wiley. research this promising field in greater detail, as we have mentioned previously.

This paper presents a number of limitations that should be addressed in future research. One relevant limitation is the cross-sectional design of our study, which means that no conclusions could be drawn about direction effects. Although we have assumed the precursor role of temperament with respect to the other constructs of our study, possibly parenting and marital adjustment do not only follow from child temperament, but also contribute to it. Thus, a longitudinal design would be needed to establish an adequate causal relation between them. With respect to the measures included in our work, our study was based only on parental report, which implied a reporter bias. Therefore, for future research, laboratory measures and other sources of information, in addition to the parents themselves, should be included in order to correct the potential subjectivity of the parents and to provide a more valid test of the hypothesized model. Indeed, other sources of variance that could affect the variables included in this work should be analyzed, such as the parents' personality, the co-parenting quality or the parents' psychopathology, among others. Finally, a longitudinal perspective of these relationships should be considered, in order to evaluate the extent to which the family environment mediates significantly the relationship between temperament and social maladjustment in other developmental stages, when the parent-child relationship dynamic is different.

Coln, K. L., Jordan, S. S., \& Mercer, S. H. (2013). A unified model exploring parenting practices as mediators of marital conflict and children's adjustment. Child Psychiatry and Human Development, 44(3), 419-29. DOI: 10.1007/s10578-012-0336-8

Crawford, N. A., Schrock, M., \& Woodruff-Borden, J. (2011). Child internalizing symtoms: contributions of child temperament, maternal negative affect, and family functioning. Child Psychiatry and Human Development, 42(1), 53-64. DOI: 10.1007/s10578-010-0202-5

Diaz, A., Eisenberg, N., Valiente, C., VanSchyndel, S., Spinard, T. L., Berger, R., Hernández, M. M., Silva, K. M. Southwort, J. (2017). Relations of Positive and Negative Expressivity and Effortful Control to Kindergarteners'Student-Teacher Relationship, Academic Engagement and Externalizing Problems at School. Journal of Research in Personality, 67, 314. DOI: $10.1016 /$ j.jrp.2015.11.002

Davis, S., Votruba-Drzal, E., \& Silk, J. (2014). Trajectories of internalizing symptoms from early childhood to adolescence: Associations with temperament and parenting. Social Development, 24(3), 501-520. DOI $10.1111 /$ sode. 12105

Delgado, B., Carrasco, M. A., González-Peña, P., \& Holgado-Tello, F. P. (2018). Temperament and behavioral problems in young children: the protective role of extraversion and effortful control. Journal of Child and Family Studies, 27(10), 3232-3240. DOI: 10.1007/210826-018-1163-8

Edwards, R. C., \& Hans, S. L., (2015). Infant risk factors associated with internalizing, externalizing, and co-occurring behavior problems in young children. Developmental Psychology, 51(4),489-99. DOI: $10.1037 / \mathrm{a} 0038800$

Eisenberg, N., Spinrad T. L., \& Eggum, N. D. (2010). Emotion related selfregulation and its relation to chidren's maladjustment. Annual Review of Clinical Psychology, 27(6), 495-525. DOI: 10.1146/annurev.clinpsy.121208.131208 
Egger, H. L., \& Angold, A. (2006). Common emotional and behavioural disorders in preschool children: presentation, nosology and epidemiology. Journal Child Psychology Psychiatry, 47(3-4), 313-37.

Else-Quest, N. M., Hyde, J.S., Goldsmith, H. H., \& Van Hulle, C. A. (2006). Gender differences in temperament. A meta-analysis. Psychological Bulletin, 132(1), 33-72. DOI: 10.1037/0033-2909.132.1.33

Fanti, K. A., \& Henrich, C. C. (2010). Trajectories of pure and co-ocurring internalizing and externalizing problems from age 2 to age 12: findings from the National Institute of Child Health and Human Development Study of Early Child Care. Developmental Psychology, 46(5), 1159-75. DOI: $10.1037 / \mathrm{a} 0020659$

Galambos, N., Barker, E., \& Almeida, D. M. (2003). Parents do matter: trajectories of change in externalizing and internalizing problems in Early Adolescence. Child Development, 74(2), 578-594. DOI: 10.1111/1467-8624.7402017

Gamliel, H. K., Dollberg, D. G., \& Levy, S. (2018). Relations between parents'anxiety symptoms, marital quality and preschoolers'externalizing and internalizing behaviors. Journal of Child and Family Studies, 27(2), 3952-3963. DOI: https://doi.org/10.1007/s10826-017-0744-2

Gerard, A. B. (1994). Parent-child relationship inventory: Manual. Los Angeles: WPS

Gilliom, M., \& Shaw, D. S. (2004). Codevelopment of externalizing and internalizing problems in early childhood. Development and Psychopathology, 16, 313-333. DOI:10.1017/S0954579404044530

Hayes, A. F. (2013). Introduction to mediation, moderation, and conditional process analysis: a regression-based approach. New York, NY: The Guilford Press.

Holm, S. (1979). A simple sequentially rejective multiple test procedure. Scandinavian Journal of Statistics, 6, 65-70.

Hosokawa, R., \& Katsura, T. (2017). Marital relationship, parenting practices and social skill development in preschool children. Child and Adolescent Psychiatry and Mental Health, 11, 1-8. DOI: 10.1186/s13034016-0139-y

Hughes, R. A., Heron, J., Sterne, J. A. C. \& Tilling, K. (2019). Accounting for missing data in statistical analysis: multiple imputation is not always the answer. International Journal of Epidemiology, 48(4), 1294-1304. DOI: 10.1093/ije/dyz032

Imai, K., Keele, L., \& Tingley, D. (2010). A general approach to causal mediation analysis. Psychological Methods, 15, 309-344. DOI: $10.1037 / \mathrm{a} 0020761$

Jonas, K., \& Kochanska, G. (2018). An imbalance of approach and effortful control predicts externalizing problems: Support for extending the dual-systems model into early childhood. Journal of Abnormal Child Psychology, 46, 1573-1583. DOI: doi.org/10.1007/s10802-018-0400-3

Karevold, E., Coplan, R., Stoolmiller, M., \& Mathiesen, K. S. (2011). A longitudinal study of the links between temperamental shyness, activity, and trajectories of internalizing problems from infancy to middle childhood. Australian Journal of Psychology, 63(1), 36-43. DOI: http://doi.org/10.1111/j.1742-9536.2011.00005.x

Karreman, A., de Haas, S.,van Tuijl, C.,van Aken M. A. G., \& Dekovic, M. (2010). Relations among temperament, parenting and problem behavior in young children. Infant Behavior and Development, 33(1), 39-49. DOI: 10.1016/j.infbeh.2009.10.008

Karreman, A., van Tuijl, C., van Aken, M. A. G., \& Dekovi, M. (2009). Predicting young children's externalizing problems: Interactions among effortful control, parenting, and child sex. Merrill-Palmer Quarterly, 55(2), 111-134. DOI: $10.1353 / \mathrm{mpq} .0 .0020$

Keenan, K., \& Shaw, D. (1997). Developmental and social influences on young girls' early problem behaviors. Psychological Bulletin, 121, 95-113.

Khele, T. J., Bray, M. A., Theodore, L. A., Zhou, Z. \& McCoach, D. B. (2004). Emotional disturbance/Social maladjustment: Why is the incidence increasing? Psychology in the Schools, 41(8), 861-865. DOI: $10.1002 /$ pits. 20042

Kim, J., \& Deater-Deckard, K. (2011). Dynamic changes in anger, externalizing and internalizing problems: Attention and regulation. Journal of Child Psychology and Psychiatry, 52, 156-166. DOI: 10.1111/j.1469-7610.2010.02301.x

Kochanska, G., \& Kim, S. (2013). Difficult temperament moderate links between maternal responsiveness and children's compliance and behavior problems in low-income families. Journal of Child Psychology and Psychiatry, 54(3), 323-332. DOI: 10.1111/jcpp.12002

Laukkanen, J., Ojansuu, U., Tolvanen, A., Alatupa, S., \& Aunola, K. (2014). Child's difficult temperament and mothers' parenting styles. Journal of Child and Family Studies, 23, 312- 323. DOI: 10.1007/s10826-013-9747-9

Lemery, K. S., Essex, M. J., \& Smider, N. A. (2002). Revealing the relation between temperament and behavior problem symptoms by eliminating measurement confounding: expert ratings and factor analyses. Child Development, 73(3), 867-882.

Lengua, L. J., \& Wachs, T. D. (2012). Temperament and risk: Resilient and vulnerable responses to adversity. In M. Zentner \& R. L. Shiner (Eds.), Handbook of temperament (pp. 519-540). New York: Guilford.

Leve, L. D., Kim, H. K., \& Pears, K. C. (2005). Childhood temperament and family environment as predictors of internalizing and externalizing trajectories from ages 5 to 17. Journal of Abnormal Child Psychology, 33(5), 505-520. DOI: $10.1007 / \mathrm{s} 10802-005-6734-7$

Lerner, R. M., Castellino, D. R., Terry, P. A., Villarruel, F. A., \& McKinney, M. H. (1995). A developmental contextual perspective on parenting. In M. H. Bornstein (Ed.), Handbook of parenting: Biology and ecology of parenting (Vol. 2, pp. 285-309). Hillsdale, NJ: Erlbaum.

Lewis, G. J., \& Plomin, R. (2015). Heritable influences of behavioural problems from early childhood to mid-adolescence: evidence for genetic stability and innovation. Psychological Medicine, 45 (10), 21712179. DOI: $10.1017 / \mathrm{S} 0033291715000173$

Little, R. J. A. (1988). A test of missing completely at random for multivariate data with missing values. Journal of the American Statistical Association, 83(404), 1198-1202.

Locke, H. J., \& Wallace, K. M. (1959). Short marital adjustment and prediction tests. Marriage and Family Living, 21, 251-255.

McCormick, M. P., O'Connor, E. E., Cappella, E., \& McClowry, S. G. (2015). Getting a good start in school: Effects of INSIGHTS on children with high maintenance temperaments. Early Childhood Research Ouarterly, 30 128-139.

DOI: https://doi.org/10.1016/j.ecresq.2014.10.006

McFadyen-Ketchum, S. A., Bates, J. E., Dodge, K. A., \& Pettit, G. (1996). Patters of Change in Early Childhood Aggressive-Disruptive Behavior: Gender Differences in Predictions from Early Coercive and Affectionate Mother-Child Interactions. Child Development, 67, 24172433.

Miner, J. L., \& Clarke-Stewart, K. A. (2008). Trajectories of externalizing behavior from age 2 to age 9: Relations with gender, temperament, ethnicity, parenting, and rater. Developmental Psychology, 44(3), 771-786. DOI: http://dx.doi.org/10.1037/0012-1649.44.3.771

Muthadie L., Zhou Q., Eisenberg N., \& Wang, Y. (2013). Predicting internalizing problems in Chinese children: the unique and interactive effects of parenting and child temperament. Development and Psychopathology, 25, 653-67. DOI: 10.1017/S0954579413000084

Muris, P., Meesters, C., \& Blijlevens, P. (2007). Self-reported reactive and regulative temperament in early adolescence: relations to internalizing and externalizing problem behavior and "Big Three" personality factors. Journal of Adolescence, 30(6), 1035-49. DOI: 10.1016/j.adolescence.2007.03.003

Muller, D., Judd, C. M. \& Yzerbyt, V. Y. (2005). When moderation is mediated and mediation is moderated. Journal of Personality and Social Psychology, 89(6), 852-863.

Nigg, J. T. (2006). Temperament and developmental psychopathology. Journal of Child Psychology and Psychiatry, 47, 395-422.

Nozadi, S. S., Spinrad, T. L., Eisenberg, N. \& Eggum-Wilkens, N. D. (2015). Associations of Anger and Fear to Later Self-Regulation and Problem Behavior Symptoms. Journal of Applied Developmental Psychology, 38, 60-69. DOI: 10.1016/j.appdev.2015.04.005

O Connor, C., Dyson, J., Codwell, F. \& Watson, R. (2018). Do universal school-based mental health promotion programmes improve the mental health and emotional well-being of young people? A literature review. Journal of Clinical Nursing, 27, 412-426. DOI: 10.1111/jocn.14078

Ortuño-Sierra, J., Aritio-Solana, R. \& Fonseca-Predero, E. (2018). Mental health difficulties in children and adolescents: The study of the SDQ in the Spanish National Health Survey 2011-2012. Psychiatry Research, 259 , 236-242. DOI: http://dx.doi.org/10.1016/j.psychres.2017.10.025 
Olson, S. L., Choe, D. E., and Sameroff, A. J. (2017). Trajectories of child externalizing problems between ages 3 and 10 years: contributions of children's early effortful control, theory of mind, and parenting experiences. Development and Psychopathology, 29, 1333- 1351. DOI: 10.1017/S095457941700030X

Olson, S., Sameroff, A., Kerr, D., López, N., \& Wellman, H. (2005). Developmental foundations of externalizing problems in young children: The role of effortful control. Development and Psychopathology, 17(1), 24-25.

Patel, T. (2019). The Role of Temperamental Fear and Parenting Quality on Emerging Internalizing and Externalizing Problems During Early Childhood (Doctoral Disertation). Retrieve from University of New Orleans Theses and Dissertations (2632). https://scholarworks.uno.edu/td/2632

Pedro, M., Ribeiro, M. T., \& Shelton, K. H. (2012). Marital satisfaction and partner's parenting practices: The mediating role of coparenting behavior. Journal of Family Psychology, 26(4), 509-522. DOI: $10.1037 /$ a0029121

Putnam, S. P., Sanson, A. V., \& Rothbart, M. K. (2002). Child temperament and parenting. In M. H. Bornstein (Ed.), Handbook of parenting, Vol. 1 Children and parenting (2nd ed., pp. 255-277). Mahwah, NJ, US: Erlbaum.

Rabinowitz, J. A., Drabick, D.A., Reynolds, M. D., Clark, D. B. \& Olino, T. M. (2016). Child temperamental flexibility moderates the relation between positive parenting and adolescent adjustment. Journal of Applied Developmental Psychology, 43, 43-53. DOI: 10.1016/j.appdev.2015.12.006

Revelle, W. (2018): Procedures for Personality and Psychological Research. Northwestern University, Evanston, Illinois, USA. Avalaible at: https://CRAN.R-project.org/package=psych Version $=1.8 .12$.

Roa, L., \& Del Barrio, V. (2001). Adaptation of the Parent-Child Relationship Inventory (PCRI) to the Spanish population. Revista Latinoamericana de Psicologia, 33(3), 329-341.

Rothbart, M. K. (1981). Measurement of temperament in infancy. Child Development, 52, 569-578.

Rothbart, M. K., \& Bates, J. E. (1998). Temperament. In W. Damon (Series Ed.) \& N. Eisenberg (Vol. Ed.), Handbook of child psychology: Vol. 3. Social, emotional and personality development (5th ed., pp. 105-176). New York: Wiley.

Rubin, K. H., Burgess, K., Kennedy, A. E., \& Stewart. S. (2003). Social withdrawal and inhibition in childhood. In E. Mash \& R. Barkley (Eds.). Child Psychopathology (pp. 372- 406). (2nd edition). New York: Guilford.

Rubin, K. H., Dwyer, K., Kim, A., Burgess, K., Booth-LaForce, C., \& RoseKrasnor, L. (2004). Attachment, Friendship and Psychosocial Functioning in Early Adolescence. The Journal of Early Adolescence, 24 (4), 326-356. DOI: 10.1177/0272431604268530

Rydel, A. M., Berlin, L., \& Bohlin, G. (2003). Emotionality, emotion regulation, and adaptation among five-to eight year old children. Emotion, 3, 30-47.

Sameroff, A. J. \& Chandler, M .J. (1975). Reproductive risk and the continuum of caretaking casualty. In F.D. Horowitz, M. Hetherington, S. Scarr-Salapatek, \& G. Siegel (Eds.), Review of Child Development Research (Vol.4). Chicago: University of Chicago Press.

Serbin, L. A., Kingdon, D., Ruttle, P. L., \& Stack, D. M. (2015). The impact of children's internalizing and externalizing problems on parenting: Transactional processes and reciprocal change over time. Development and Psychopathology, 27(4), 969-86. DOI: 10.1017/S0954579415000632

Shigeto, A., Mangelsdorf, S. C., \& Brown, G. L. (2014). Roles of family cohesiveness, marital adjustment, and child temperament in predicting child behavior with mothers and fathers. Journal of Social and Personal Relationships, 31, 200-220. DOI: 10.1177/0265407513490586

Silva, F. \& Martorell, M. C. (1982). BAS 1.2. Batería de Socialización (para profesores y padres). Madrid: TEA.

Simmonds, J., \& Rothbarth, M. K. (2004). The Temperament in Middle Childhood Questionnaire (TMCQ): A computerized self-report measure of temperament for ages 7-10. Poster session presented at the Occasional Temperament Conference, Athens, GA.

Stanley, S. M., Ragan, E. P., Rhoades, G. K., \& Markman, H. J. (2012). Examining changes in relationship adjustment and life satisfaction in marriage. Journal of Family Psychology, 26, 165-170. DOI: $10.1037 / \mathrm{a} 0031134$

Tingley, D., Yamamoto, T., Hirose, K., Keele, L., \& Imai, K. (2014). Mediation: R package for Causal Mediation Analysis. Journal of Statistical Sof tware, $\quad 59, \quad 1-38 . \quad$ Available at: https://imai.fas.harvard.edu/research/files/mediationR2.pdf

Thomas, A., \& Chess, S. (1977). Temperament and Development. New York: Brunner/Mazel.

van der Bruggen, C.O., Stams, G. J. M., Bögels, S. M., \& PaulussenHoogeboom, M. C. (2010). Parenting behavior as a mediator between young children's negative emotionality and their anxiety/depression. In fant and Child Development, 19 (4), 354-365. DOI: 10.1002/icd.665.ç

van Prooijen, D., Hutteman, R., Mulder, H., van Aken, M. \& Laceulle, O. (2018). Self- control, parenting, and problem behavior in early childhood: A multi-method, multi- informant study. Infant Behavior and Development. 50, 28-41. DOI: 10.1016/j.infbeh.2017.11.001

Walters, G. (2014). Pathways to early delinquency: Exploring the individual and collective contributions of difficult temperament, low maternal involvement, and externalizing behavior. Journal of Criminal Justice, 42(4), 321-326. DOI: 10.1016/j.jcrimjus.2014.04.003

Wang, F. L., Eisenberg, N., Valiente, C., \& Spinrad, T. L. (2015). Role of temperament in early adolescent pure and co-occurring internalizing and externalizing problems using a bifactorial model: Moderation by parenting and gender. Development and Psychopathology, 9, 1-18. DOI: 10.1017/S0954579415001224

Witting, S. M. O. \& Rodriguez, C.M. (2019a). Emerging behavior problems: Bidirecional relations between maternal and paternal parenting styles with infant temperament: Developmental Psychology, 55(6), 1199-1210. DOI: https://doi.org/10.1037/dev0000707

Witting, S. M. O. \& Rodriguez, C. M. (2019b). Interaction between maternal parenging styles with infant temperament in emerging behavior problems. Infant Behavior and Development, 57. DOI https://dpi.org/10.1016/j.infbeh.2019.04.005

White, I. R. \& Carlin, J. B. (2010). Bias and efficiency of multiple imputation compares with complete-case analysis for missing covariate values. Statistics in Medicine, 28, 2920-2931.

Zadeh, Z. Y., Jenkins, J., \& Pepler, D. (2010). A transactional analysis of maternal negativity and child externalizing behavior. International Journal of Behavioral Development, 34(3), 218-228. DOI http://dx.doi.org/10.1177/0165025409350953.

Zhao, S., Chen, X., \& Wang, L. (2015). Maternal parenting and social, school, and psychological adjustment of migrant children in urban China. International Journal of Behavioral Development, 39(6), 541-551. DOI: 10.1177/0165025415576815

Zimet, D. M., \& Jacob, T. (2001). Influences of marital conflict on child adjustment: Review of theory and research. Clinical Child and Family Psychology Review, 4, 319-335. 